\title{
Adhesion of Pancreatic Beta Cells to Biopolymer Films
}

\author{
S. Janette Williams ${ }^{3}$, Qun Wang ${ }^{1}$, Ronal R. MacGregor ${ }^{4}$, Teruna J. Siahaan ${ }^{2}$, Lisa Stehno- \\ Bittel $^{3, *}$, and Cory Berkland ${ }^{1,2,{ }^{*}}$ \\ ${ }^{1}$ Department of Chemical and Petroleum Engineering, the University of Kansas, Lawrence, KS \\ ${ }^{2}$ Department of Pharmaceutical Chemistry, the University of Kansas, Lawrence, KS \\ ${ }^{3}$ Department of Physical Therapy \& Rehabilitation Sciences, the University of Kansas Medical \\ Center, Kansas City, KS \\ ${ }^{4}$ Department of Anatomy and Cell Biology, the University of Kansas Medical Center, Kansas City, \\ KS
}

\begin{abstract}
Dramatic reversal of Type 1 diabetes in patients receiving pancreatic islet transplants continues to prompt vigorous research concerning the basic mechanisms underlying patient turnaround. At the most fundamental level, transplanted islets must maintain viability and function in vitro and in vivo and should be protected from host immune rejection. Our previous reports showed enhancement of islet viability and insulin secretion per tissue mass for small islets $(<125 \mu \mathrm{m})$ as compared to large islets $(>125 \mu \mathrm{m})$, thus, demonstrating the effect of enhancing the mass transport of islets (i.e. increasing tissue surface area to volume ratio). Here, we report the facile dispersion of rat islets into individual cells that are layered onto the surface of a biopolymer film towards the ultimate goal of improving mass transport in islet tissue. The tightly packed structure of intact islets was disrupted by incubating in calcium-free media resulting in fragmented islets, which were further dispersed into individual or small groups of cells by using a low concentration of papain. The dispersed cells were screened for adhesion to a range of biopolymers and the nature of cell adhesion was characterized for selected groups by quantifying adherent cells, measuring the surface area coverage of the cells, and immunolabeling cells for adhesion proteins interacting with selected biopolymers. Finally, beta cells in suspension were centrifuged to form controlled numbers of cell layers on films for future work determining the mass transport limitations in the adhered tissue constructs.
\end{abstract}

\section{Keywords}

islet; beta cell; thin film; biopolymers; cell adhesion

\section{Introduction}

Diabetes mellitus currently rivals heart disease and cancer as a major killer of US citizens. Islet transplantation represents a promising option for restoring euglycemia in people with type 1 diabetes [1]. Unfortunately, donor shortage is further confounded by current protocols, which require 1-3 donor pancreata per recipient [2]. Extending the utility of donor tissue is imperative. Isolated islets exhibit precipitous cell death (in vitro and in vivo) over the course of days [3,4], due in part to reduced access to oxygen and nutrients within

(C) 2009 Wiley Periodicals, Inc.

*To whom correspondence should be addressed. berkland@ku.edu. 
the explanted islet interior. The transport of glucose, glucagon, and insulin is also greatly reduced in explanted islets versus native tissue, which is densely vascularized (capillary spacing $\sim 50 \mu \mathrm{m}$ ) [5].

The physical characteristics of islets have been verified as an important determinant of transplant success. Twenty years ago, researchers described in detail the size and shape of islets and determined a method for estimating islet volume [6]. Since then, research groups have modeled the transport of oxygen, glucose, and insulin within the islet and/or through biomedical devices containing islets [7,8]. Most recently, Dulong and others have modeled the insulin production of islets arranged within fibers or sheets, directly demonstrating the need for using geometrical tissue configuration to improve islet viability and function [9]. Our recent studies also indicated that larger islets exhibit increased necrosis when exposed to hypoxic conditions. Indeed, nearly all beta cells died when islet diameter exceeded 100 $150 \mu \mathrm{m}[10]$. The resulting oxidative stress associated with necrosis may also aggravate apoptosis and immune response upon transplantation [11].

Retarded transport of glucose and insulin also diminishes the functionality of pancreatic islets. The glucose gradient within an islet causes peripheral cells to contact much higher concentrations of glucose than those contained in the islet core $[12,13]$. A similar argument applies to the transport of insulin or glucagon out of the islet [14]. Arranging beta cells on films may provide one mechanism to increase cell exposure to the highest glucose concentration (i.e. eliminating the "core" where death occurs) while simultaneously enhancing insulin transport out of the reconstructed tissue.

Based on this rationale, research efforts were designed to control the thickness of pancreatic beta cell layers and elucidate adhesion onto biopolymer films with the goal of increasing the number of functional cells transplanted. As a first step toward this broader goal, we report methods to disperse islets into individual cells and layer them onto biopolymer films as a means to fabricate multilayered tissue constructs (Figure 1). A library of biopolymers was screened for cell binding and several were identified that promoted adhesion of rat beta cells. Morphological analysis of cells and staining of cell adhesion molecules provided some clues as to the nature of biopolymer/cell interactions. Finally, rat pancreatic islets dispersed into individual or small groups of cells were centrifuged onto selected biopolymer films to produce islet tissue constructs exhibiting a controllable thickness of beta cells.

\section{Materials and Methods}

\section{Materials}

All polymer materials in Table 1 were commercially available and used as received. Methylene chloride (HPLC grade, Fisher) was used for film casting for polyester and polyanhydride samples. Ethanol (HPLC grade, Fisher) was used for film casting CellForm ${ }^{\mathrm{TM}}$. All other films used water as the solvent. Other chemicals employed were research grade.

\section{Preparation of films}

Films from different materials were produced by a casting/solvent evaporation technique or simply as monolayer coatings to the culture plasticware employed (e.g. laminin, surfactants, etc.). Solutions of film materials, $1 \mathrm{mg} / \mathrm{ml}$, were prepared with distilled water, ethanol (CellForm ${ }^{\mathrm{TM}}$ ), or methylene chloride (poly (bL-lactic-co-glycolic acids) (PLGA) and polyanhydrides). When using methylene chloride, drying conditions were sufficiently fast to avoid dissolution of the plastic in tissue culture plates. Solutions were sonicated in a sonication bath for 30 seconds (3510R-MT, Branson Ultrasonics Co., U.S.A.) and left to stand until trapped air bubbles were removed. Subsequently, $1.0 \mathrm{~mL}$ of solution was 
dropped into each well of a 6-well plate (Fisher) to make films. In some cases, $0.1 \mathrm{~mL}$ of solution was dropped into each well of a 96-well plate to produce films. These films were dried at room temperature for $48 \mathrm{~h}$ until a constant weight was obtained. Some films were ionically crosslinked by subsequent exposure to $1 \% \mathrm{NaOH}$ or $1 \%$ tripolyphosphate for chitosan and $2 \% \mathrm{CaCl}_{2}$ for alginate. After crosslinking for 30 minutes, the films were washed by distilled water.

Two layer films were made using the same method. In each well of a 9-well plate (or 96well plate), the bottom layer was produced using $1 \mathrm{ml}$ of $1 \mathrm{mg} / \mathrm{mL}$ 50:50 PLGA solution $(0.58 \mathrm{dL} / \mathrm{g}$, dissolved in methylene chloride). After a dry film was produced, another $0.6 \mathrm{~mL}$ of $1 \mathrm{mg} / \mathrm{mL}$ solution of the second polymer (dissolved in distilled water) was dropped on the surface of the dry PLGA film. This two layer film was dried until reaching a constant weight. All the experiments were conducted a minimum of ten times.

\section{FTIR analysis of films}

The FTIR spectra of all polymer films were recorded using a Disposable Polyethylene Card (Spectra-Tech, Inc., U.S.A.) on an FTIR spectrometer (Prota Type, ABB Bomem, Canada). Films were cast onto these cards using the techniques described above.

\section{Islet isolation and dispersion}

To isolate pancreatic islets, DA and Sprague Dawley rats (purchased from Harlan SpragueDawley) were anesthetized by an intraperitoneal injection of ketamine and xylazine. The peritoneal cavity was exposed and the pancreatic ductal connection to the intestine clamped. The pancreas was cannulated in situ via the common bile duct, and distended by pumping a cold solution of collagenase into the duct. Subsequently, the distended pancreas was excised, transferred to centrifuge tubes and incubated for $40 \mathrm{~min}$ with gentle tumbling at $37^{\circ} \mathrm{C}$. The washed digest was passed through a screen and sedimented in a refrigerated centrifuge. The pellet was mixed with Histopaque (density $=1.1085$, Sigma Diagnostics Inc., St. Louis, $\mathrm{MO}$ ) and centrifuged. Islets were cleaned of exocrine tissue by sedimentation at $1,000 \mathrm{~g}$ through 5\% BSA with either Hanks Balanced Salt Solution (HBSS) or L15 media, and placed into Petri dishes containing Leibovitz's L-15 culture medium and $10 \%$ fetal bovine serum (FBS). The islets were maintained at room temperature. Fractionation of islets into small $(<125 \mu \mathrm{m})$ and large $(>125 \mu \mathrm{m})$ islets has been reported previously [13]. Isolated islets were digested to viable cell suspensions by placing them in 15 or $50 \mathrm{ml}$ centrifuge tubes containing calcium-magnesium free HBSS $+4.8 \mathrm{mM}$ Hepes with papain $(5$ units $/ \mathrm{mL}$ final concentration). After incubation on a rotator at $37^{\circ} \mathrm{C}$ for 30 minutes, the islets were pipetted, dispersing them into single cells. The cells were transferred to CMRL 1066 as the final culture media. When necessary, islets or dispersed beta cells were identified with dithizone labeling following published procedures [14]. Interestingly, nearly all viable cells collected after islet fragmentation and isolation were beta cells. It is possible that this fragmenting procedure was more selective for beta cells over other cells (e.g. alpha, delta, endothelial) that normally appear in whole islet isolates.

\section{Viability measurements}

Apoptosis versus necrosis experiments were completed with YO-PRO-1 and Propidium iodide (Vybrant Apoptosis Assay, Molecular Probes) for intact islets and Sytox and Calcein (Molecular Probes) for islet fragments and single beta cells. For the single cell assay, beta cells were placed with phosphate buffered saline (PBS) in the Attofluor Chamber (Molecular Probes) on an Olympus Fluoview 300 laser confocal microscope. All images were collected within 20 minutes of removal of the cells from media. Three simultaneous images were collected for each islet using $\mathrm{He}: \mathrm{Ne}$ and Argon lasers and a third bright-field image. Live/dead analysis was completed by identifying the cells in the field using 
transmitted light. Subsequently the number of live, necrotic or apoptotic cells was counted and the percent of the total calculated. When individual cells could not be identified, percentages were calculated based on area, rather than cell counts. Experiments were conducted in triplicate and the average and standard deviation calculated.

\section{Characterization of beta cell adhesion}

Cell adhesion to biopolymer films must be determined to avoid dissociation of the tissue from the biopolymer backing during surgical implantation. To this end, a wide variety of biopolymers were screened for interactions with beta cells (Table 1). Most of these materials dissolved in deionized water at neutral $\mathrm{pH}$. Chitosan required a lower $\mathrm{pH}$ of $\sim 6$ to dissolve (hydrochloric acid was used) and other materials required organic solvents. Cellform ${ }^{\mathrm{TM}}$ was dissolved in ethanol and PLGA, poly(sebacic anhydride), and Poly[(1,6-biscarboxyphenoxy) hexane] were dissolved in dichloromethane. The polymers alginate, gelatin, and polyvinyl alcohol formed physically stable films upon drying. Cell adhesion to alginate crosslinked with calcium was also studied. Aliquots $(50 \mu \mathrm{L})$ of each stock solution were added to three individual wells in 96-well plates and left to evaporate or vacuum dried, thus, depositing a thin film at the bottom of each well. Residual solvent content was not determined; however, negative effects resulting from solvent presence, such as cell death, were not observed. Several proteins that are offered commercially to promote cell adhesion on well plates (fibronectin, laminin, and collagen IV.) were screened for cell adhesion as well. These materials adsorb to the well surface and were simply added to the wells in the same manner and residual water was removed and the wells were air dried. Similarly, the amphiphilic molecules polyvinylpyrrolidone and Pluronic $₫$ were adsorbed as films to the polystyrene plates. Double layer films were formed by drying a first layer of 50:50 PLGA $(0.58 \mathrm{dL} / \mathrm{g})$ and then depositing a second material as specified in Table 2. FTIR spectra for selected single and double layer films were collected and are available as supplementary information.

A homogeneous suspension of islet cells was transferred to 6 or 96-well plates containing biopolymer films, incubated overnight, and washed three times to remove unbound beta cells. Wells without films were used as controls. Cell viability and adhesion were quantified by incubating a $500 \mu \mathrm{L}$ volume of beta cells with live/dead fluorophores as described above. Optical microscopy was used to quantify beta cell adhesion and coverage from multiple representative areas of the biopolymer film. A minimum of three fields of view $(260,000$ $\mu \mathrm{m}^{2}$ ) was used for quantification. Cell counts were normalized to counts from wells without biopolymer film to minimize the potential of variability between explanted rat islets. This data was recorded as relative cell count. Relative surface area coverage was quantified from these representative images by measuring the surface area of individual cells at the cell/gel interface using Olympus Fluoview software. This value represents the relative spreading of adherent cells on that particular biopolymer. Live/dead cell counts were conducted as described above. Beta cell adhesion and viability were tracked for $\sim 1$ week.

Optical and fluorescent microscopies were employed to evaluate cell morphology utilizing appropriate fluorescent markers to characterize cell adhesion. Antibodies used to assess adhesion were against: integrin $\beta 1$, E-cadherin, and $\beta$-cadherin (BD Transduction Laboratories), and ZO-1, occludin, claudin-1, catenin (Zymed Laboratories). Individual beta cells were incubated on the films as described above for 48 hours. Cells were rinsed in PBS prior to fixation in 2\% paraformaldehyde (Fisher Scientific, Palatine, IL). Fixed cells were rinsed with PBS 3 times. If antibody epitopes were intracellular, cells were permeabilized with $1 \%$ Triton X-100 (Sigma) and rinsed repeatedly before blocking in 10\% goat or donkey serum (Jackson Immunoresearch Laboratories). 
Cells were incubated with a primary antibody listed above in 5\% non-fat dry milk (Bio-Rad) solution overnight in a humidified box at $4^{\circ} \mathrm{C}$ at manufacturer recommended concentrations. Subsequently, cells were rinsed with PBS before incubation in a dark humidified box with secondary antibody conjugated to Rhodamine Red or Cy 2 (Jackson ImmunoResearch Laboratories) for 1 hour at room temperature. Cells were rinsed 3 times and allowed to air dry in the dark before mounting. Images were captured using an Olympus Fluo-View 300 confocal microscope. The focal plain of the microscope was directed to the cell/film interface. Experiments were performed in triplicate.

\section{Production of multilayered beta cell constructs with controlled cell thickness}

Islets were isolated from rat pancreata and dispersed as described above. The dispersed cells were suspended in CMRL 1066 media $(0.5 \mathrm{ml})$ with 5\% FBS and $1 \%$ PenicillinStreptomycin and were added to individual wells in a 96- well plate. Plates with 50:50 PLGA in the wells were centrifuged at room temperature at $\sim 750 \mathrm{~g}$ to layer the cells onto the film surface. Cells were allowed to culture onto the biopolymer film at the bottom of the well overnight to encourage adhesion. Half of the media was removed from each well, replaced with media containing the cell suspension and again layered onto the film by centrifugation. This was repeated three times. Additional layers of islet cells were attached to the film for each iteration. To control the thickness of the beta cell layer, either the volume of cell culture added to each well and/or the number of aliquots added to each well in repeated deposition cycle was controlled.

\section{Results}

\section{Verification of cell viability before and after dispersion}

Isolated, intact islets were prepared for viability analysis by staining with YO-PRO1 and propridium iodide. Figure 2 illustrates the differences in cell death in the large islets when compared to small islets prepared using the same techniques. The red staining of cells indicated death from necrosis, while green staining indicated cell death from apoptosis. Due to the fact that cells die rapidly in intact large islets, methods were developed to enhance mass transport by obtaining individual beta cells and reconfiguring cells as multiple layers.

By using a combination of calcium depletion and low concentration of papain (5 units $/ \mathrm{mL}$ ), islets were dispersed into individual or small groups of cells without mechanical rotation. Rapid islet dispersion with minimal loss of viable cells was achieved $(98 \% \pm 7$ viability; $\mathrm{n}=10$ ). The procedure utilizes papain in conjunction with calcium depletion for dispersing beta cells [15] since cell adhesion molecules (e.g. E-cadherin) hold the islet together, but require divalent metals to function [16]. The effects of papain alone $(5 \mathrm{u} / \mathrm{mL})$, calcium depletion alone, and a combination of the two on islet fragmentation were analyzed (Figure 3). Cells were stained using a live/dead cell assay where green indicates apoptosis and red serves as a marker for necrosis. As is commonly done, simply incubating islet isolates with papain resulted in a decrease in islet diameter and produced spherical islet morphology (Figure 3A). A common concern when using papain is the enzyme's effect on cell viability (for more detailed information, see reference 15). Alternatively, incubating islet isolates in calcium-magnesium free HBSS produced irregular, web-like islet fragments exhibiting a similar average diameter as the papain-digested islets (Figure 3B). Culturing these islet fragments in calcium-free media with papain for 30 minutes resulted in consistently dispersed individual or small groups of cells (Figure 3C). Figure 3D illustrates a large field of cells and fragments dispersed using the papain-calcium depletion method. These cells were stained with Sytox and Calcein resulting in live cells stained green and dead cells stained red. Supernatants and plated cells were also stained with dithizone as a marker for 
beta cells, which confirmed that nearly all cells were indeed beta cells (Figure 4). This method of islet fragmentation resulted in cells that were highly viable (Figure 3D).

The high viability observed in dispersed beta cells stands in stark contrast to beta cell viability in native large islets, which drops significantly in the first few days after isolation. Figure 5 illustrates the viability measurements of single cells and intact islets isolated from the same rats. The cells/islets were cultured simultaneously and aliquots removed every two days to measure viability. The large islets $(>125 \mu \mathrm{m})$ maintained in culture typically exhibited a significant percentage of necrotic $(\sim 12.6 \%)$ and apoptotic $(\sim 6.3 \%)$ cells after only four days with cell viability decreasing over time (Figure 5). Smaller islets $(<125 \mu \mathrm{m})$ exhibited $>95 \%$ viability at 6 days implicating the increased surface area as a mechanism to improve the viability of islets. The dispersed beta cells also possessed high viability ( $>95 \%)$ in culture for a similar period of time. Previously, we have reported extended viability measurements that corroborate the findings reported here [13]. These results underscore the importance of using basic techniques such as calcium depletion immediately upon isolation to improve the viability of islets in culture.

\section{Screening of biopolymers for beta cell adhesion and viability}

Beta cell adhesion to biopolymer films was quantified in terms of relative cell count, that is, the total number of cells for a given film normalized to the number of adherent cells in blank wells. Figure 6 contrasts the differences in cells attached to chitosan (A) and PLGA (B). As suspected, many of the mildly hydrophobic polymers performed well for adhering beta cells as did most of the commercially available materials used for coating plates (Table 2). For example, the biodegradable polyester PLGA consistently demonstrated cell adhesion 4-10 fold greater than empty wells. Methyl ester end-capped PLGA is more hydrophobic than the carboxyl end-capped PLGA; however, no clear difference was observed between these two polymer types. The lowest molecular weight PLGA exhibited the greatest cell adhesion despite the carboxyl end-cap, which might have been suspected to repel the negatively charged cell membrane/extracellular matrix. PLGA polymers coated with a second polymer as two layer films also demonstrated improved cell adhesion relative to empty wells. Cell adhesion to naturally occurring polymers was sporadic. The natural glycoprotein, laminin, a major component of basement membranes and extracellular matrix, demonstrated excellent beta cell adhesion. Collagen IV and gelatin, present at high concentration in connective tissue; chitosan, a cationic polysaccharide derived from the shells of crustaceans; and alginate, an anionic polysaccharide derived from brown algae commonly used for islet encapsulation, only displayed moderate cell adhesion. CellForm ${ }^{\mathrm{TM}}$, which is routinely used as a plate coating material to promote cell adhesion, also exhibited only moderate cell adhesion.

Optical micrographs confirmed that cell morphology was affected by the biopolymer. Beta cells were sparsely plated onto films so that there was limited cell-to-cell contact. In this way the interaction of individual cells with the polymer was isolated. Cell morphology changed slightly with the polymer type. For example, beta cells on laminin and PLGA demonstrated increased spreading and exhibited a ruffled morphology (Figure 4 and Figure $6 \mathrm{~B})$. Cells on chitosan $(\mathrm{Mw}=100 \mathrm{kDa})$ exhibited a smooth, rounded surface suggesting a reduced contact area with the biopolymer film (Figure 6A). To further study this phenomenon, the cell surface area at the cell/film interface was measured for 40-50 cells per plate in triplicate. The surface area covered by individual cells on different biopolymers varied depending on material type (Figure 7). The data suggested a minor correlation between the number of adherent cells and the relative surface area covered by individual cells, but the trend was not statistically significant. 
Immunolabeled proteins showed clear differences in their distribution pattern; however, there was no evidence of any changes in the distributions of these proteins as a result of interactions with different biopolymers. E-cadherin showed a punctate staining pattern, which did not change if cells were plated on Pluronic ${ }^{\circledR}$ (Figure 8A) or other polymers such as PLGA (not shown). The adhesion protein, $\mathrm{ZO}-1$ stained in a ring-like pattern around the edge of the cell for the most adherent biopolymers (Figure 8B). Claudin staining was extremely diffuse at the cell/film interface with no areas of high or low density (Figure 8C). Integrin $\beta 1$ and $\beta$ catenin staining illustrated focal adhesion points on the cell surface with high densities of each of these proteins (Figure $8 \mathrm{D}$ and $8 \mathrm{E}$ ). Occludin had a more diffuse distribution with regions of higher density (Figure 8F). These results were suggestive of complex binding events to biopolymers that involved several different cell adhesion proteins, which underscores the importance of defining the appropriate cell-biopolymer interactions to promote adhesion and cell viability [17].

\section{Control of multiple cell layers on biopolymers}

The methods used to screen biopolymers for beta cell adhesion were modified to create a multilayer beta cell construct consisting of a controlled number of layers of beta cells. In order to bind layers of beta cells onto a film of polymer, cell suspensions were sequentially centrifuged onto the film surface. In this manner, the number of cell layers was discretely controlled (Figure 9). Incremental layers of cells were attached to two types of PLGA (the best PLGA performers from Table 1). Cells remained attached with repeated media changes. Cell attachment was probably mediated by cell-cell adhesion as well as cell adhesion to films. Media containing calcium was used for these experiments since calcium participates in cell-cell adhesion molecules such as E-cadherin [16]. To further demonstrate the morphology of the outermost cell layer, surface topography images were collected on a film with five layers of cells (Figure 9C). Dark areas indicate open areas in the cell layer and light areas indicate cells above the imaged layer. Multilayers of beta cells contained occasional void spaces between cells, but yielded a consistent surface topology. Cell viability studies indicated that essentially all cells were viable after layering and no additional cell death was found after several days. The results suggest that the increased porosity of the layered tissue constructs improve transport and cell viability.

\section{Discussion}

Islet transplants have yielded sporadic success stories; however, great strides still need to be made for this procedure to be routinely efficacious. Recent advances in living donor transplants have invigorated additional enthusiasm for increasing the donor pool and identifying better "matches" to reduce immune rejection $[18,19]$. Actualizing this enthusiasm into medical procedures with improved outcomes will require making full use of donated pancreatic tissue, especially when attempting to extract islets from a living donor [20]. This report outlines a facile method for dispersing islets into cells for adhesion to a biopolymer film towards an ultimate goal of maximizing the viability of donated tissue in a device that is easy to handle and implant.

As mentioned before, individual beta cells should represent the highest achievable free surface area for transporting oxygen, glucose, etc.; however, several important criteria preclude iJanuary 1, 2002mplantation of a suspension of beta cells. Although implantation of a beta cell suspension would be simple, recovery in the event of patient complication would be unfeasible. These foreign cells may also be rapidly phagocytosed and removed from the host body by professional antigen presenting cells. In addition, a multitude of evidence verifies the necessity of cell-cell contacts as a requirement for islet viability and function [21]. For example, disruption of the extracellular matrix was implicated in decreased beta cell viability in explanted canine islets [3]. In another report, interrupting 
beta cell adhesion mediated by E-cadherin eliminated glucose-stimulated intracellular increases in calcium and insulin secretion resulting in a significant reduction of beta cell number, proliferation rate, and pancreatic insulin content in two-day old mice [22]. Finally, rat beta cells within an isolated islet possessed synergistic response times to glucose. This finding, among others, supports a mechanism of communication between beta cells to coordinate insulin secretion [23]. This primitive communication network includes cells besides beta cells (e.g. alpha, delta, etc.), which may be even more important in human islets, which do not exhibit the same cellular organization as rat islets [24].

The flexible approach of dispersing islets on films may facilitate strategies aimed to improve tissue function and attenuate immunorejection. For example, reported techniques such as immunoisolation $[25,26]$ or local delivery of anti-immunorejection agents $[27,28]$ could be incorporated into this scheme. Currently, approaches such as islet encapsulation only add additional diffusive barriers in an attempt to allow the passage of glucose and insulin while screening out antibodies or immune cells [29]. Improving cell viability in the initial transplant is also crucial. The geometric arrangement of islet tissue reported here may enhance the exposure of cells to a free surface where oxygen and nutrients are more readily available. Enhanced tissue geometry may also extend implant life and may further reduce the amount of tissue required for successful transplantation, since much of the tissue in transplanted islets may quickly perish. Finally, alternative sources of insulin producing cells (e.g. genetically modified or differentiated stem cells) may also benefit from this approach [30].

\section{Conclusions}

Islet transplantation has provided glimpses of hope that this medical procedure will one day provide late stage diabetics with renewed health. A key limitation to transplant success is sustaining the viability of explanted islets. We report a basic engineering approach to geometrically rearrange islet tissue into multiple layers of controlled thickness on biopolymer films towards the goal of improving mass transport and tissue viability. Improved cell viability was noted for dispersed beta cells and small islets compared to large islet isolates. The reported islet dispersion method resulted in the loss of only a few percent of beta cells. A wide variety of biopolymers were screened for adhering dispersed beta cells. PLGA polymers and laminin generally promoted cell adhesion, which seemed to be mediated though several cell adhesion molecules. A variety of cell adhesion molecules were found to participate in the binding of beta cells to polymer films. In particular, E-cadherin, integrin $\beta 1$ and $\beta$ catenin showed punctate staining patters on many of the films while $\mathrm{ZO}-1$ stained in a ring-like pattern around the cell periphery for the most adhesive polymers. Other cell adhesion proteins such as claudin and occludin did not appear to participate in binding as evidenced by diffuse cellular staining patterns. Centrifuging dispersed beta cells onto selected biopolymer films allowed the production of a controlled number of cell layers on the film surface depending on the suspension volume and concentration of cells. Multilayer beta cell constructs were produced while maintaining $\sim 100 \%$ cell viability. Our future studies aim to quantify the persistence of cell viability and insulin production kinetics for different numbers of beta cell layers as compared to intact islets. Ultimately, this platform affords exciting opportunities for incorporating controlled release or immunoprotection strategies as extensions of the work reported here.

\section{Supplementary Material}

Refer to Web version on PubMed Central for supplementary material. 


\section{Acknowledgments}

We are indebted to the Juvenile Diabetes Research Foundation for providing an Innovation Award and the Emilie Rosebud Diabetes Research Foundation for supporting this work. We acknowledge other support in the lab from the NIH (1R03 AR054035-01A1, P20 RR016443 and P20 RR015563), the DOD (W81XWH-07-1-0021), the American Heart Association and the Cystic Fibrosis Foundation. We also thank Prof. Balaji Narasimhan of Iowa State University for providing polyanhydrides and Prof. Russ Middaugh for the use of equipment.

\section{References}

1. JDRF. From Research to Reality: Case Statement. 2004 Feb 06 [cited 2004 08/04/04]. Available from: www.jdrf.org

2. NIDDKD. Collaborative Islet Tranplant Registry, Annual Report; Sponsored by the National Institutes of Diabetes \& Digestrive \& Kidney Diseases; 2004. p. 41-81.

3. Rosenberg L, Wang R, Paraskevas S, Maysinger D. Structural and functional changes resulting from islet isolation lead to islet cell death. Surgery. 1999 Aug; 126(2):393-398. [PubMed: 10455912]

4. Choi SE, Choi KM, Yoon IH, Shin JY, Kim JS, Park WY, et al. IL-6 protects pancreatic islet beta cells from pro-inflammatory cytokines-induced cell death and functional impairment in vitro and in vivo. Transpl Immunol. 2004 Jun-Jul; 13(1):43-53. [PubMed: 15203128]

5. Wayland H. Microcirculation in pancreatic function. Microsc Res Tech. 1997 Jun 1-15; 37(5-6): 418-433. [PubMed: 9220421]

6. Bonnevie-Nielsen V, Skovgaard LT. Pancreatic islet volume distribution: direct measurement in preparations stained by perfusion in situ. Acta Endocrinol (Copenh). 1984 Mar; 105(3):379-384. [PubMed: 6199936]

7. Dulong JL, Legallais C. Contributions of a finite element model for the geometric optimization of an implantable bioartificial pancreas. Artif Organs. 2002 Jul; 26(7):583-589. [PubMed: 12081516]

8. Nomura M, Shichiri M, Kawamori R, Yamasaki Y, Iwama N, Abe H. A mathematical insulinsecretion model and its validation in isolated rat pancreatic islets perifusion. Comput Biomed Res. 1984 Dec; 17(6):570-579. [PubMed: 6391804]

9. Dulong JL, Legallais C. A theoretical study of oxygen transfer including cell necrosis for the design of a bioartificial pancreas. Biotechnol Bioeng. 2006 Aug 8.

10. Giuliana M, Moritz W, Bodmer E, Dindo D, Kugelmeier P, Lehmann R, et al. Central necrosis in isolated hypoxic human pancreatic islets: evidence for postisolation ischemia. Cell Transplantation. 2005; 14:67-76. [PubMed: 15789664]

11. Bottino R, Balamurugan AN, Tse H, Thirunavukkarasu C, Ge X, Profozich J, et al. Response of human islets to isolation stress and the effect of antioxidant treatment. Diabetes. 2004 Oct; 53(10): 2559-2568. [PubMed: 15448084]

12. Kauri LM, Jung SK, Kennedy RT. Direct measurement of glucose gradients and mass transport within islets of Langerhans. Biochem Biophys Res Commun. 2003 May 2; 304(2):371-377. [PubMed: 12711325]

13. MacGregor RR, Williams SJ, Tong PY, Kover K, Moore WV, Stehno-Bittel L. Small rat islets are superior to large islets in in vitro function and in transplantation outcomes. Am J Physiol Endocrinol Metab. 2006 May; 290(5):E771-E779. [PubMed: 16303846]

14. Mythili DM, Patra SS, Gunasekaran S. Culture prior to transplantation preserves the ultrastructural integrity of monkey pancreatic islets. J Electron Microsc (Tokyo). 2003; 52(4):399-405. [PubMed: 14599102]

15. Balamurugan AN, Chang Y, Fung JJ, Trucco M, Bottino R. Flexible management of enzymatic digestion improves human islet isolation outcome from sub-optimal donor pancreata. Am J Transplant. 2003 Sep; 3(9):1135-1142. [PubMed: 12919094]

16. Hauge-Evans AC, Squires PE, Persaud SJ, Jones PM. Pancreatic beta-cell-to-beta-cell interactions are required for integrated responses to nutrient stimuli: enhanced $\mathrm{Ca} 2+$ and insulin secretory responses of MIN6 pseudoislets. Diabetes. 1999 Jul; 48(7):1402-1408. [PubMed: 10389845]

17. Weber LM, Hayda KN, Haskins K, Anseth KS. The effects of cell-matrix interactions on encapsulated beta-cell function within hydrogels functionalized with matrix-derived adhesive peptides. Biomaterials. 2007 Jul; 28(19):3004-3011. [PubMed: 17391752] 
18. Matsumoto S, Tanaka K, Strong DM, Reems JA. Efficacy of human islet isolation from the tail section of the pancreas for the possibility of living donor islet transplantation. Transplantation. 2004 Sep 27; 78(6):839-843. [PubMed: 15385802]

19. Tan M, Kandaswamy R, Sutherland DE, Gruessner RW. Laparoscopic donor distal pancreatectomy for living donor pancreas and pancreas-kidney transplantation. Am J Transplant. 2005 Aug; 5(8):1966-1970. [PubMed: 15996246]

20. Smith RM, Gale EA. Survival of the fittest? Natural selection in islet transplantation. Transplantation. 2005 May 27; 79(10):1301-1303. [PubMed: 15912094]

21. Soria B, Andreu E, Berna G, Fuentes E, Gil A, Leon-Quinto T, et al. Engineering pancreatic islets. Pflugers Arch. 2000 May; 440(1):1-18. [PubMed: 10863992]

22. Yamagata K, Nammo T, Moriwaki M, Ihara A, Iizuka K, Yang Q, et al. Overexpression of dominant-negative mutant hepatocyte nuclear fctor-1 alpha in pancreatic beta-cells causes abnormal islet architecture with decreased expression of E-cadherin, reduced beta-cell proliferation, and diabetes. Diabetes. 2002 Jan; 51(1):114-123. [PubMed: 11756330]

23. Schuit FC, In't Veld PA, Pipeleers DG. Glucose stimulates proinsulin biosynthesis by a dosedependent recruitment of pancreatic beta cells. Proc Natl Acad Sci U S A. 1988 Jun; 85(11):38653869. [PubMed: 3287379]

24. Cabrera O, Berman DM, Kenyon NS, Ricordi C, Berggren PO, Caicedo A. The unique cytoarchitecture of human pancreatic islets has implications for islet cell function. Proc Natl Acad Sci U S A. 2006 Feb 14; 103(7):2334-2339. [PubMed: 16461897]

25. Cui W, Barr G, Faucher KM, Sun XL, Safley SA, Weber CJ, et al. A membrane-mimetic barrier for islet encapsulation. Transplant Proc. 2004 May; 36(4):1206-1208. [PubMed: 15194418]

26. Zimmermann H, Zimmermann D, Reuss R, Feilen PJ, Manz B, Katsen A, et al. Towards a medically approved technology for alginate-based microcapsules allowing long-term immunoisolated transplantation. J Mater Sci Mater Med. 2005 Jun; 16(6):491-501. [PubMed: 15928863]

27. Lee DY, Park SJ, Nam JH, Byun Y. A combination therapy of PEGylation and immunosuppressive agent for successful islet transplantation. J Control Release. 2006 Jan 10; 110(2):290-295. [PubMed: 16324765]

28. Ridgway DM, White SA, Nicholson ML, Kimber RM. Pancreatic islet cell transplantation: progress in the clinical setting. Treat Endocrinol. 2003; 2(3):173-189. [PubMed: 15966566]

29. Chang TM. Therapeutic applications of polymeric artificial cells. Nat Rev Drug Discov. 2005 Mar; 4(3):221-235. [PubMed: 15738978]

30. Baharvand H, Jafary H, Massumi M, Ashtiani SK. Generation of insulin-secreting cells from human embryonic stem cells. Dev Growth Differ. 2006 Jun; 48(5):323-332. [PubMed: 16759282]

Biopolymers. Author manuscript; available in PMC 2010 August 1. 

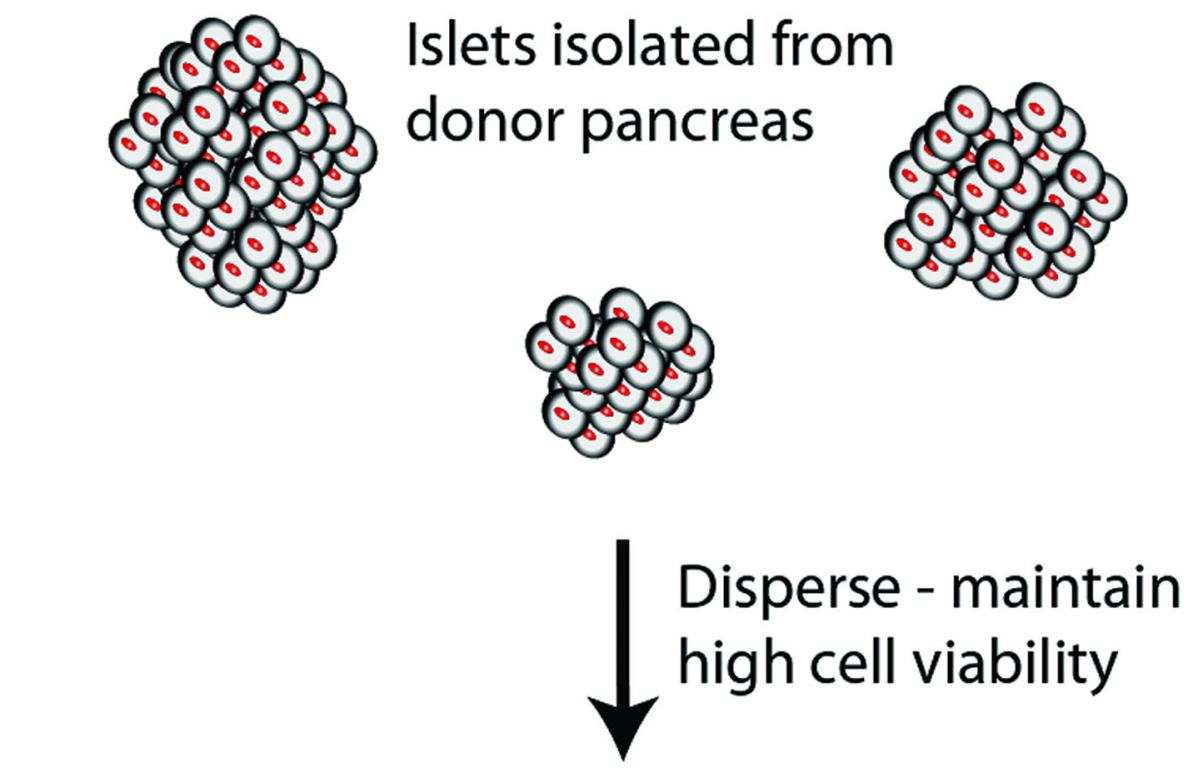

0

(2)

- 0

(-)

- Ob

(0)

( $)$
- 0

800

$\odot$<smiles>O=S1(=O)OC=[SH]1</smiles>

6

(2)<smiles>[O-]</smiles>

(2)

0<smiles>[O-]</smiles>

- 000

Centrifuge onto biomaterial patch

0

(6)

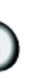

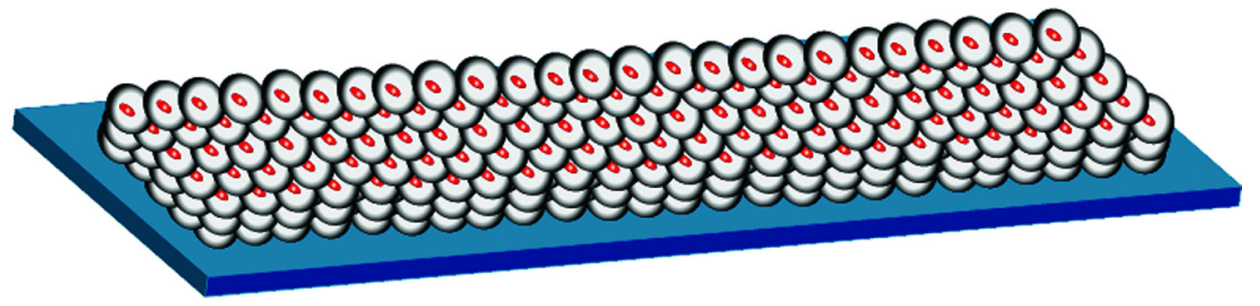

Figure 1.

Schematic representation of the production of a multilayer beta cell construct. 


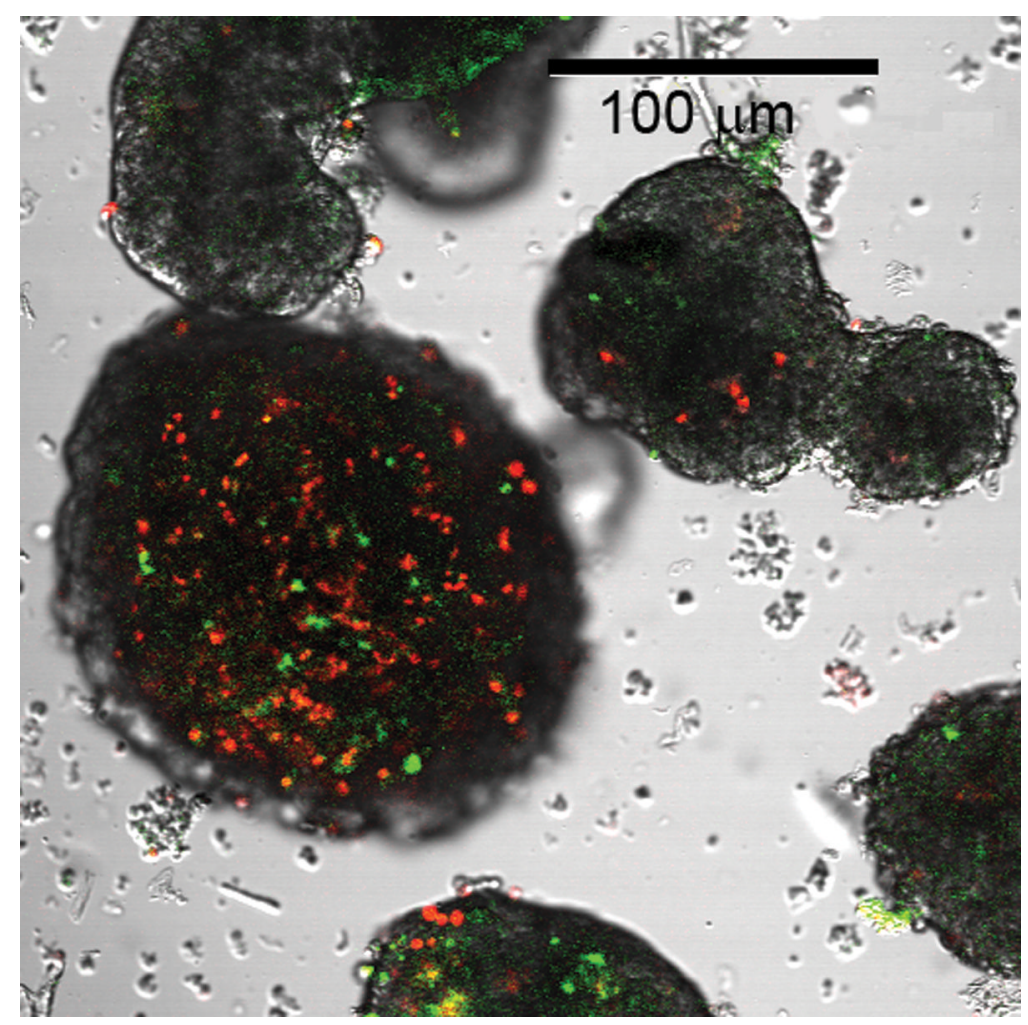

Figure 2.

Comparison of small and large rat islets isolated from the same pancreas stained for viability. The large islet on the left illustrates substantial numbers of dead cells (red and green). Small islets in the same field demonstrate a much lower percentage of dead cells. 

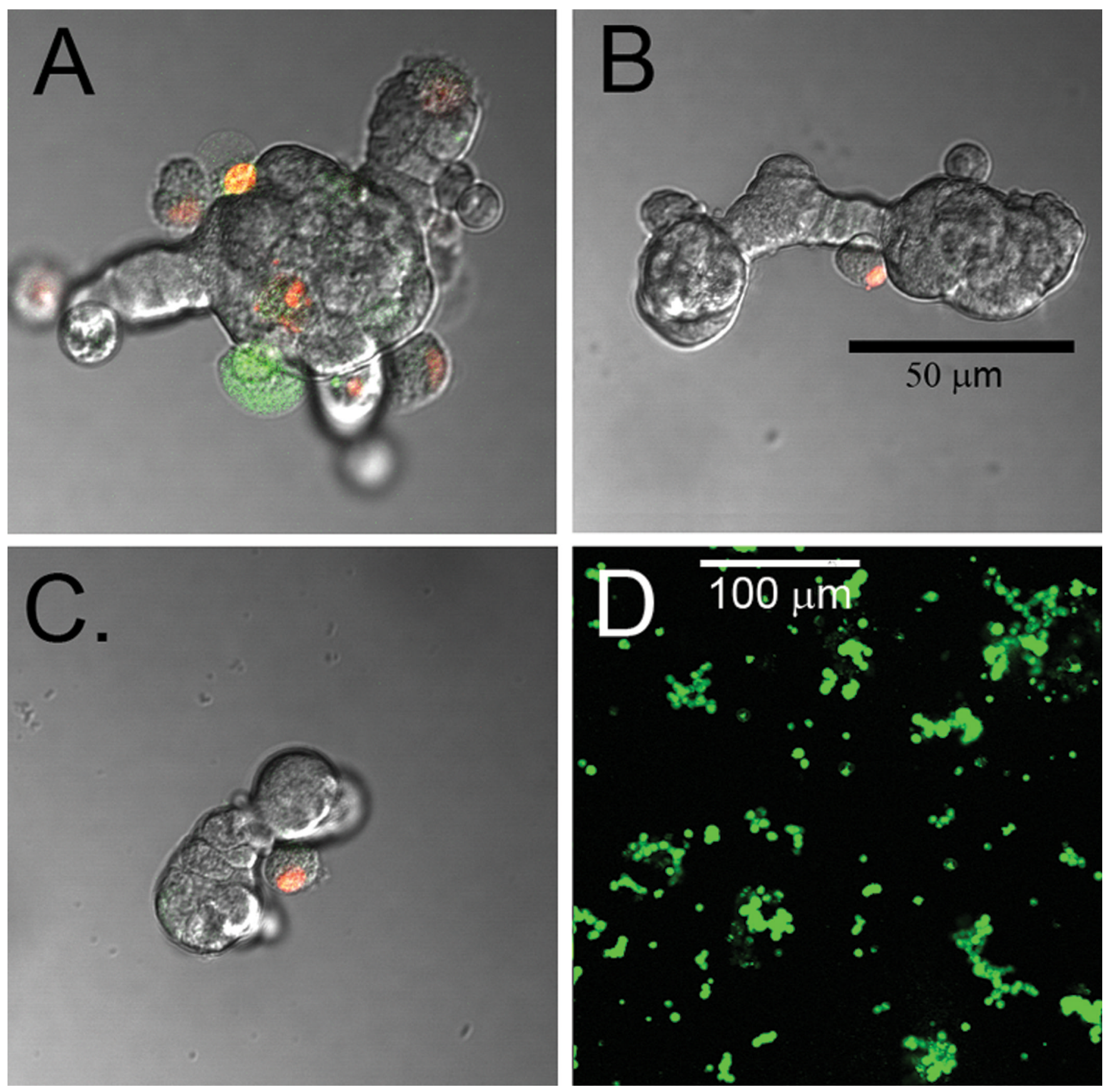

Figure 3.

Fragments of islets and a dispersion stained for live and dead cells. A) Fragment maden from a large islet using the enzyme dispersion method. B) Removal of calcium from the median also resulted in fragmentation of the islet. C) Utilizing both calcium depletion and enzymen resulted in smaller islet fragments. D) When islets were dispersed further via gentle pipetting,n single beta cells resulted. Figure A-C were stained with red indicating cells dead due to necrosis, $\mathrm{n}$ and green illustrating cell death due to apoptosis. The majority of cells dispersed into fragmentsn remained viable. Cells in D were stained with Sytox/ Calcein. All green cells are viable usingn this procedure and dead cells are marked as red. The scale bar in B applies to figures A-C. 


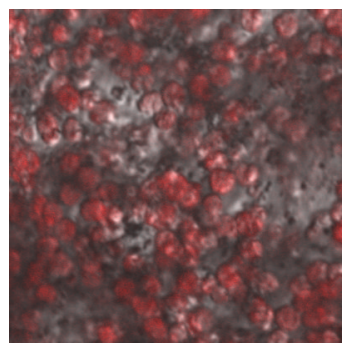

Figure 4.

Dispersed islet cells were plated at a high density on laminin and stained with dithizone to identify beta cells. 


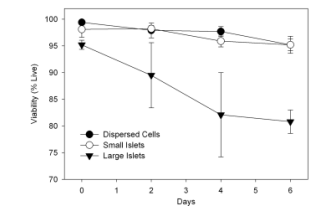

Figure 5.

Cell viability for cultured large $(>125 \mu \mathrm{m})$ rat islets, small $(<125 \mu \mathrm{m})$ rat islets, and dispersed beta cells. The decreased viability of large islets is statistically significant ( $\mathrm{p}<$ 0.05 ) beyond day 3. Experiments were performed in triplicate. 

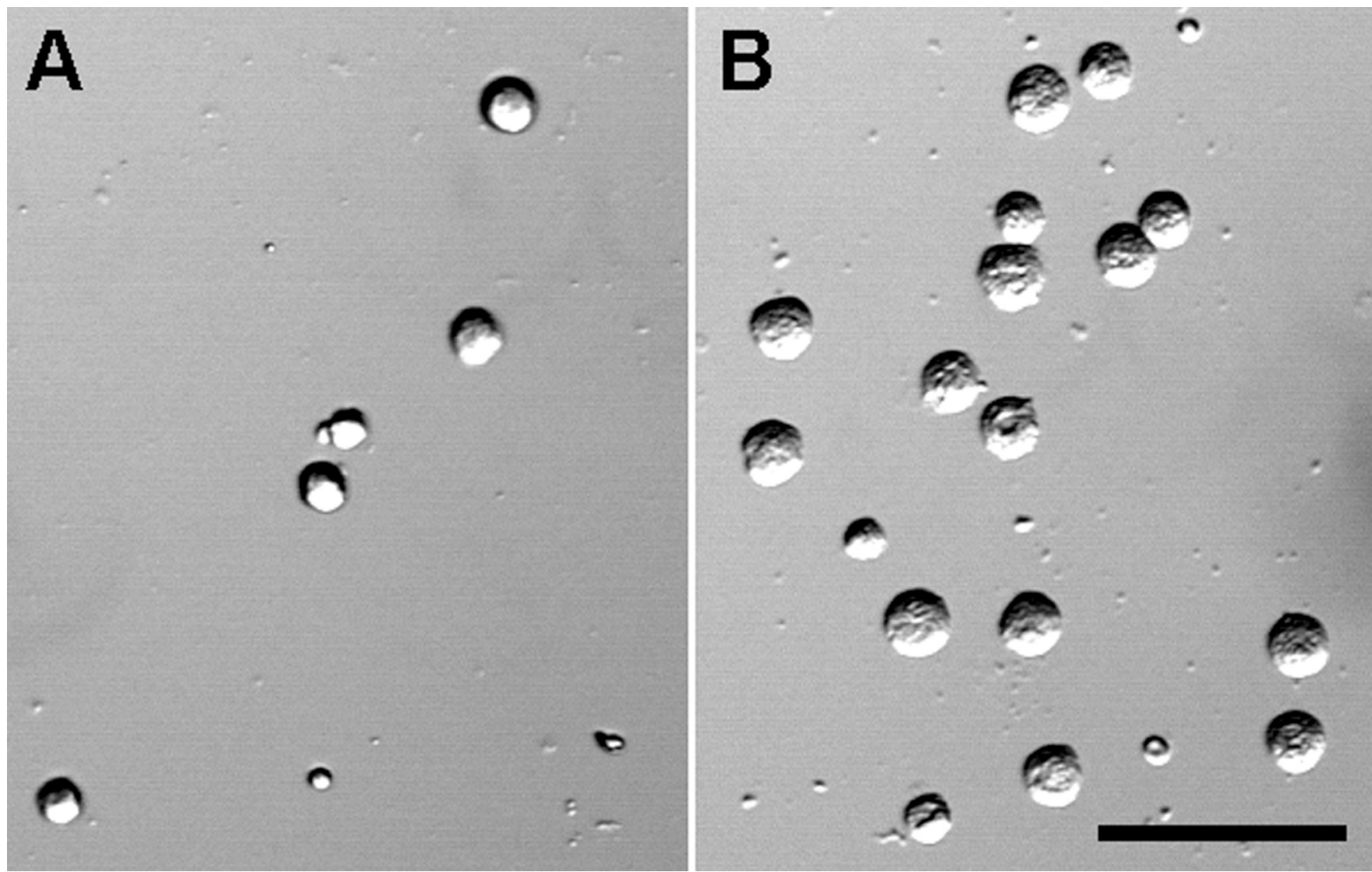

Figure 6.

A) Beta cells sparsely plated on PLGA show a higher density of attached cells after washing, indicating greater cell adhesion to the biopolymer film. B) Fewer cells remained attached to chitosan after washing. 


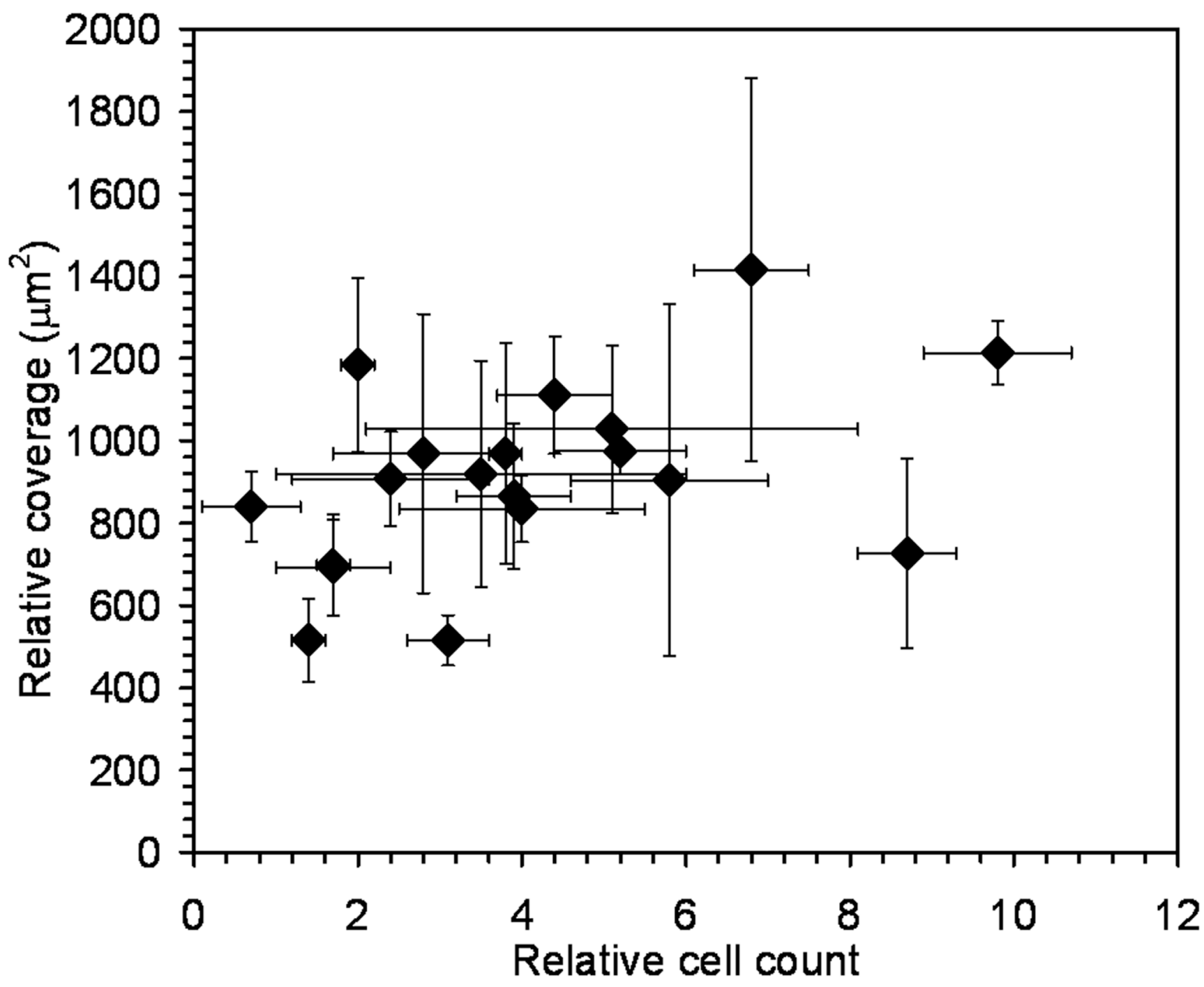

Figure 7.

Relative cell count values compared to the relative surface area covered by the cells (Table 2). Values are plotted with the standard deviation as error bars. Experiments were performed in triplicate. 


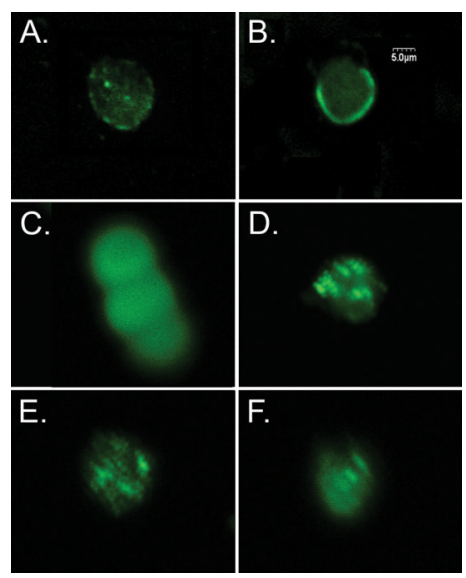

Figure 8.

Beta cells were plated on polymers and immunolabeled for adhesion proteins. (A) Cell plated on Pluronic ${ }^{\circledR}$ stained for E cadherin. (B) Cell on PEG immunolabeled for ZO-1. (C) Three cells on PLGA-carboxyl immunolabeled for claudin. (D) Cell on dextran sulfate immunolabeled for integrin $\beta 1$ (E) Cell on chitosan immunolabeled for $\beta$ catenin (F) Cell plated on dextran sulfate immunolabeled for occludin. 


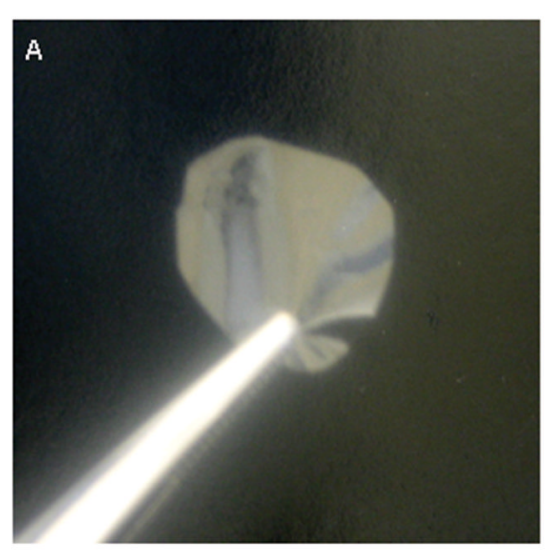

\section{Thickness}

\section{Patch Cross-Section}

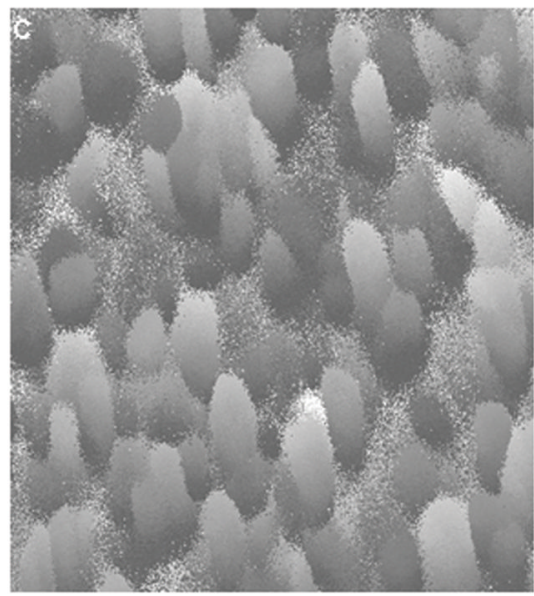

1-2 islet

cells

2 islet

cells

\section{3-4 islet \\ cells}

\section{4-5 islet} cells
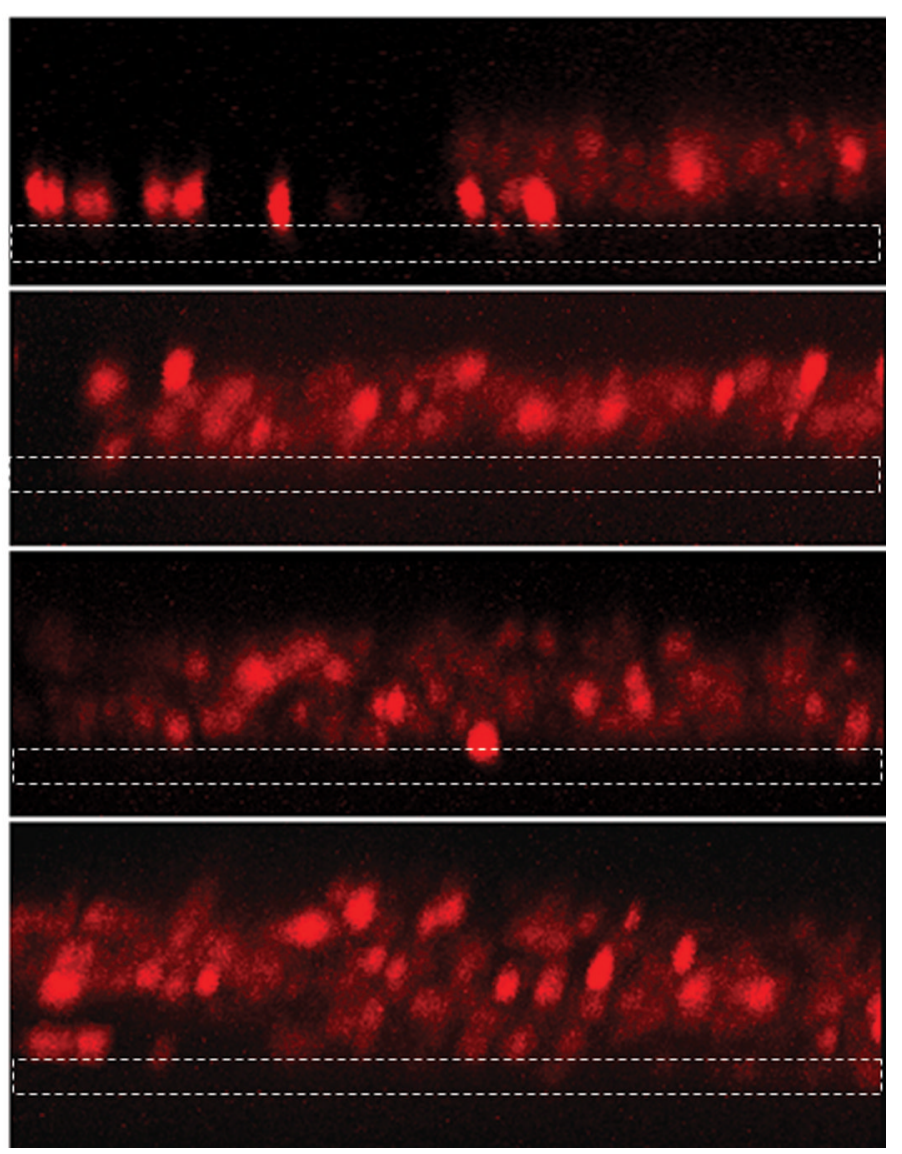

Figure 9.

A) An optical image of a typical biopolymer film prior to cell deposition. B) A vertical cross-section of beta cell layers of discrete thickness, reported as the number of cell diameters 23 (beta cell diameter $\sim 10$ microns, stained using dithizone). Images were obtained by laser scanning confocal microscopy, dotted white lines depict the film location. C) An intensity plot showed that the surface topology of the top cell layer did not typically differ by more than 1 cell diameter and that complete coverage of the biopolymer substrate was attained (obtained by LSCM). Circular shapes are cells and similar shades represent similar cell height (lighter shades are higher, darker shades are lower). 
Table 1

Biopolymers employed in this study.

\begin{tabular}{|c|c|c|}
\hline Materials & Source & Mw \\
\hline 50:50 $\mathrm{PLGA}^{l}$ & Absorbable Poly. Int. & $32 \mathrm{kDa}$ \\
\hline 50:50 PLGA & Absorbable Poly. Int. & $82 \mathrm{kDa}$ \\
\hline 50:50 PLGA & Absorbable Poly. Int. & $156 \mathrm{kDa}$ \\
\hline 50:50 PLGA-COOH & Absorbable Poly. Int. & $10 \mathrm{kDa}$ \\
\hline 50:50 PLGA-COOH & Absorbable Poly. Int. & $5.5 \mathrm{kDa}$ \\
\hline Polyvinypyrrolidone & Sigma & $360 \mathrm{kDa}$ \\
\hline Polyethylenimine & Aldrich & $25 \mathrm{kDa}$ \\
\hline Pluronic ${ }^{\circledR}$ F68 & Anatrace & $8.4 \mathrm{kDa}$ \\
\hline Cellform Polymer & MP Biomedicals, Inc. & na \\
\hline Gelatin & Fisher & $155 \mathrm{kDa}$ \\
\hline Dextran Sulfate & Fisher & $8 \mathrm{kDa}$ \\
\hline Dextran Sulfate & Fisher & $500 \mathrm{kDa}$ \\
\hline Poly (ethylene-alt-maleic anhydride) & Polysciences, Inc. & $100 \mathrm{kDa}$ \\
\hline Poly (vinyl alcohol) & Polysciences, Inc. & $25 \mathrm{kDa}$ \\
\hline Chitosan & Polysciences, Inc. & $15 \mathrm{kDa}$ \\
\hline Chitosan & Polysciences, Inc. & $8 \mathrm{kDa}$ \\
\hline Alginate & Acros Organics & $2,000 \mathrm{kDa}$ \\
\hline Fibronectin & BD Biosciences & $450 \mathrm{kDa}$ \\
\hline Collagen IV & BD Biosciences & na \\
\hline Laminin & BD Biosciences & na \\
\hline Poly(sebacic anhydride) & Prof. Narasimhan ${ }^{2}$ & na \\
\hline Poly[(1,6-bis-carboxyphenoxy) hexane] & Prof. Narasimhan & na \\
\hline
\end{tabular}

Biopolymers. Author manuscript; available in PMC 2010 August 1. 
Table 2

Relative cell count for the biopolymers investigated is represented as the number of adherent cells normalized to the number of adherent cells in empty wells.

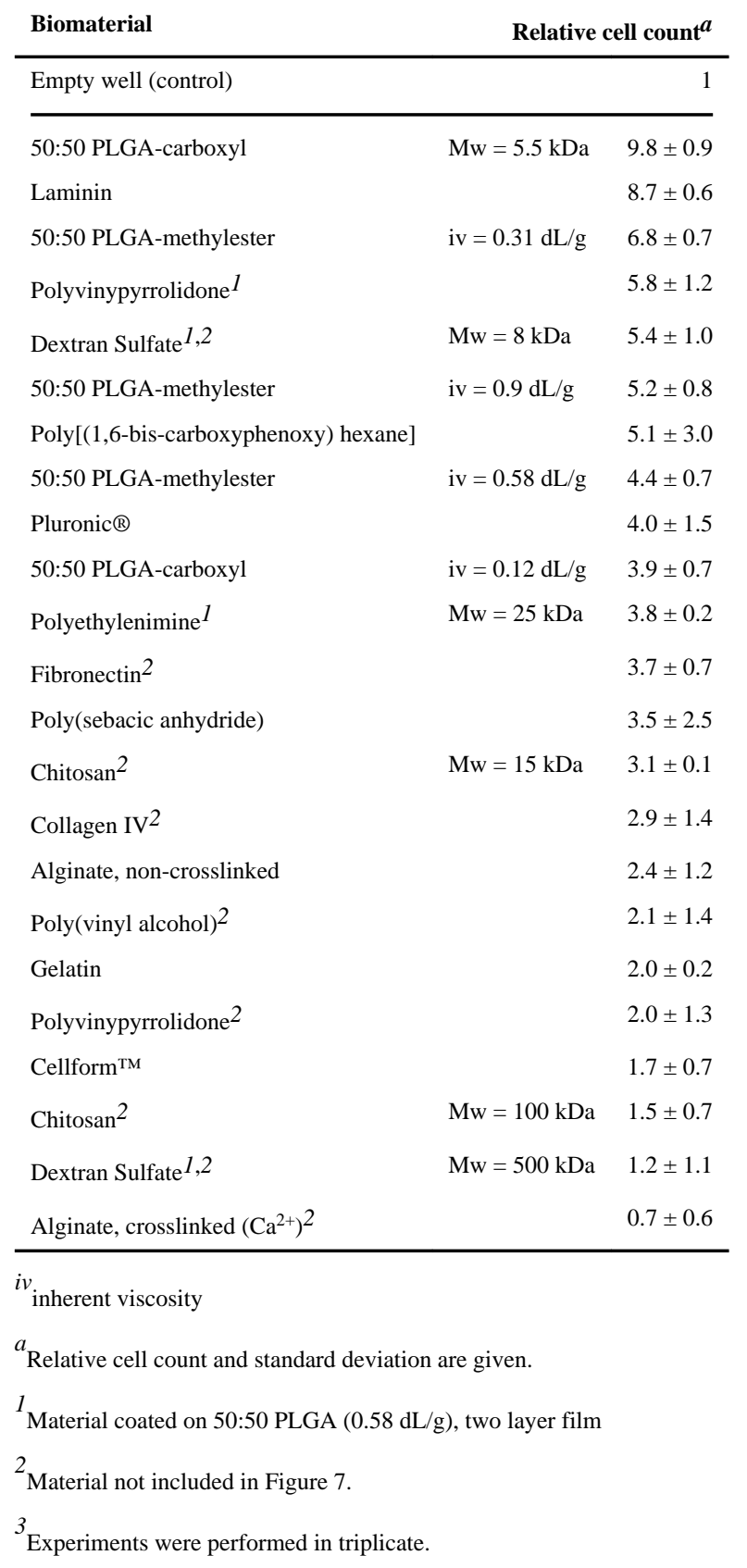

